\title{
Intelectuales de la disidencia y literatura «Samizdat» en Checoslovaquia
}

\author{
Marina Casanova
}

\begin{abstract}
RESUMEN
Una de las principales fuentes para conocer la experiencia totalitaria de la

segunda mitad del siglo xx en

Checoslovaquia es la literatura "samizdat". A lo largo de toda la historia checa, los intelectuales han representado el espiritu de la nación y han tenido un importante papel en la politica. del pais. La literatura "Samizdat" surge cuando la palabra es silenciada y el escritor crea sus obras sin esperar ninguna recompensa. La literatura "samizdat" permitió a los disidentes liberarse de la censura y constituirse en un contrapoder: el poder simbólico de la palabra y del desafio moral.
\end{abstract}

PALABRAS CLAVE

Checoslovaquia. Totalitarismo.

Literatura "samizdat". Intelectuales.

Disidentes. Censura. Contrapoder.

\section{ABSTRACT}

One of the main sources to know the totalitarian experience of the second half of the xxth century is "Samizdat Literature». All along czech history, intellectuals have represented the nation's spirit, and have had an important role in politics. "Samizdat Literature" springs up when writers lose their freedom and achieve their works without expecting any reward. "Samizdat Literature" provides dissidents to get free from censorship and to set up an anti-establishment power: the symbolic power of the written word and of the moral challenge.

KEY WORDS

Czechoslovakia. Totalitarian.

"Samizdat Literature". Intellectuals.

Dissidents. Censorship.

Anti-establishment power.

* UNED 
Una de las principales fuentes para conocer la experiencia totalitaria de la segunda mitad del siglo xx en Checoslovaquia es la literatura "samizdat". En un país donde los intelectuales siempre han encarnado el espíritu de la nación y han tenido un importante papel en la política, la literatura se vio otorgada la misión de iluminar y de dirigir a los ciudadanos. En los momentos históricos en los que la palabra estuvo silenciada, el discurso de los intelectuales checos causó un gran impacto en una sociedad que nunca estuvo tan marcada por la religiosidad, como en el caso de Polonia. y que les convirtió en los representantes de las aspiraciones nacionales.

El término "samizdat" es de origen ruso y quiere decir "hecho por uno mismo". Fue utilizado por primera vez en 1950 por el poeta ruso Nikolai Glazkov, para designar un ejemplar de poemas escritos a máquina y encuadernado rudimentariamente por el propio autor. La palabra "samizdat", que no tiene equivaiente en español, adquirió con el tiempo un significado más amplio en función de las circunstancias históricas de aquellos países que sufrieron la censura de los regímenes totalitarios, y fue un medio para que los escritores condenados al silencio publicaran sus obras en libros hechos en casa. «Mi mujer tenía entre sus manos unas hojas de papel cebolla con una escritura ilegible. No tenía entre sus manos un libro, sino un "libro-nolibro", objeto curioso de nuestra cultura nacional de los años setenta del siglo veinte, objeto desconocido con anterioridad, libro hecho en casa. Y porque la vida me ha enseñado a entender los libros, creo que los «libros-nolibros" han evitado la muerte de la literatura checa", escribe Milan Šimečka ${ }^{1}$.

La literatura "samizdat" tuvo un alcance muy distinto en los países de Europa Central y del Este en función de su situación política e histórica. En Hungria, fue considerada como una actividad privada, pero tolerada por las autoridades. En Polonia, la fuerza de "Solidaridad" hizo posible que las editoriales "samizdat" abarcaran numerosos periódicos, revistas y libros. Por el contrario, en Checoslovaquia las publicaciones "samizdat" no fueron tan numerosas y tuvieron un círculo de lectores muy reducido. Ese aislamiento produjo una mayor introspección en la literatura checa y, en consecuencia, una mayor independencia de los escritores disidentes que crearon obras de gran calidad comparabies a las obras de los padres del despertar nacional a mediados del siglo xIX. Esa es la opinión de Šimečka cuando escribe: «Por alguno de ellos se pagó muy caro, y se sigue pagando muy caro, con la cárcel, con la humillación, con la ansiedad. Pero a pesar de todo, no hay duda de que los "libros-nolibros" serán los que dejen testimonio de la época que hemos vivido. Porque el lenguaje oficial que

Śmečka, MILAN: «Knihy-neknihy», en “Sólo pro psaci stroj”.Colonia. INDEX. 1984. pág. 206. 
suena a palabras huecas no interesa a nadie. Gracias a los "libros-nolibros" tengo la impresión de formar parte de los privilegiados que los han leido" ". Si bien fueron los rusos quienes divulgaron el término "samizdat", los checos lo perfeccionaron e hicieron de él un arte ${ }^{3}$.

Para los checos, el sentimiento de identidad nacional, la "chequidad», viene determinado por el lenguaje. Durante tres siglos, después de la derrota de la "Montaña Blanca» en 1620, la identidad checa quedó relegada al mundo rural, donde se mantuvieron los simbolos de su cultura y de su lengua para no sucumbir al dominio de la lengua y de la cultura alemanas. La "chequidad" estuvo caracterizada por una abundante literatura que popularizó los tópicos patrióticos, las leyendas, las canciones, el folklore.

Seis meses después de la derrota de la Montaña Blanca, el 11 de junio de 1621, veintisiete hidalgos, caballeros y burgueses fueron ejecutados en la plaza de la Ciudad Vieja por traición. Cuando el caudillo de la rebelión, el conde Schlik, subió al cadalso, llevaba en la mano un libro: el "Kšaft” - Testamento- de Comenius. Todos ellos estaban destinados a permanecer en la memoria del pueblo checo. Aquellas ejecuciones se convirtieron en el símbolo de la humillación y de la capacidad de adaptación de los ciudadanos.

Sin embargo, esa capacidad de adaptación ha sido considerada por algunos autores como complicidad. Todas las transiciones que se han realizado en Checoslovaquia contaron con la complicidad de vencedores y vencidos. El primer presidente de la República, Tomáš Masaryk, pactó con los vencedores de la I Guerra mundial las condiciones para la creación del nuevo Estado. En 1938, el presidente Edvard Beneš aceptó las cláusulas de los Acuerdos de Munich sin oponer resistencia. Cuando los alemanes invadieron el país en marzo de 1939, el presidente del Tribunal Supremo, Emil Hácha, fue nombrado Presidente del Protectorado y firmó un acuerdo con Hitler. El comandante de las fuerzas alemanas negoció la retirada de sus tropas en mayo de 1945 con el Comité Nacional checo. El presidente Beneš entregó el poder a los comunistas en 1948. Dubček firmó los acuerdos de Moscú en 1968 y, finalmente, el Foro Cívico aceptó que un comunista, Marian Calfa, dirigiera el primer gobierno democrático después de la revolución de terciopelo. Esa capacidad de adaptación ha sido incluso criticada por miembros de la "Carta 77 " como Petr Pithar, que no comprende que se califique a la revolución de 1989 de terciopelo, porque en su opinión, ni siquiera hubo revolución ${ }^{4}$.

Ibidem.

Pavel TIGRID, citado por:H.Gordon Skilling: "Samizdat and an Independant Society in Central and Eastern Europe".Columbus. Ohio State University Press.1989 pág. 11.

“ Gellner, ERNST: "Encuentros con el nacionalismo». Madrid. Alianza Universal. 1994. pág. 135. 
En opinión del filósofo checo, Jan Patočka, la lengua no determina la grandeza de una nación, pero en el desaparecido reino de Bohemia los checos se vieron obligados a identificarse con su lengua y con sus tradiciones para mostrar sus esperanzas de originalidad. La lucha emprendida para emanciparse durará hasta mediados del siglo xIX, cuando surge el despertar nacional checo. En esa nueva sociedad, el elemento nuevo y decisivo no es la utilización de la lengua en sí misma, sino la formación de toda una sociedad que se define por su utilización ${ }^{5}$.

Durante el siglo $x x$, con dos guerra mundiales y una guerra fría a lo largo de casi medio siglo, el pueblo checoslovaco ha vivido demasiadas convulsiones, revoluciones y contrarrevoluciones. Todos participaron como protagonistas o como comparsas, pero cualquier ciudadano checo que tenga actualmente más de cuarenta años, tuvo la posibilidad de tomar, en un momento dado, una buena o mala decisión ${ }^{6}$.

Checoslovaquia ha conocido todos los regímenes políticos que han existido en Europa durante el siglo xx: la democracia liberal de la Primera República de 1918 a 1938; el nazismo de 1938 a 1945; el difícil socialismo democrático de 1945 a 1948; el período estalinista de 1948 a 1960; el despertar democrático de la Primavera de Praga y la invasión soviética en 1968; la "normalización» de Husák hasta 1989, fecha en la que tuvo lugar la Revolución de terciopelo y, finalmente, la división del país en dos Estados independientes, República Checa y República Eslovaca.

Uno de los más grandes escritores de la literatura checa, Karel Capek, comparó la historia de su país con el ritmo de las estaciones en el Ártico: algunas horas de luz frente a una interminable noche. La luz empezó a brillar en 1918 y se apagó en 1938. Capek murió ese mismo año y, afortunadamente, no sufrió lo siete años de tinieblas en los que se vio sumergido el país. En 1945 la luz de un nuevo gobierno democrático iluminó Checoslovaquia, pero volvería a apagarse en 1948. Veinte años de una larga noche sumieron al pueblo en el miedo, en la indiferencia, en la desesperanza. En 1968 llegó la Primavera de Praga iluminando el camino hacia la libertad, pero la esperanza de los ciudadanos se corivirtió en derrota cuando los tanques soviéticos invadieron el país. Con la «normalización " las tinieblas cubrieron el cielo de Checoslovaquia y el ciudadano dejó de existir.

5 Patočka, JAN: “L'idée de l'Europe en Bohême». Grenoble. Ed. Jérôme Milion. 1991.

6 Precan, VILEM: “Les chemins menant à la révolution democratique", en "Le Printemps tchècoslovaque, 1968».Bruxelles. Ed. Complexe. 1999. pág. 312. 
Su propia historia moldeó a Checoslovaquia de una forma muy particular, no es extraño que también moldeara el carácter de sus habitantes. Algunos se mostraron dispuestos a aceptar cualquier situación y se plegaron a las exigencias de los gobernantes del momento. Otros hicieron suya la decisión de "vivir en la verdad». Recogiendo la tradición moral del pensamiento del primer Presidente de la República, T.G. Masaryk, se enfrentaron a un régimen que empleaba todos los medios para combatirles. En una sociedad tan decepcionada y oprimida, un pequeño grupo de intelectuales lucharon solamente con la fuerza de sus palabras.

«Para que una persona pueda soportar la carga de su propio destino, y una nación la de su historia, hace falta tener paciencia y perseverancia", palabras de Ivan Klima que definen muy bien el comportamiento de los checos a lo largo de su historia ${ }^{7}$. El personaje de Hašek, el soldado Švejk, representa con su disimulada estupidez, la capacidad para soportar las situaciones más difíciles y hacerlas más llevaderas. $Y$ no es casual que, en la misma época, otro genial escritor, Kafka, trasladase a sus obras el sentimiento del ciudadano perdido en el mundo de lo absurdo. Tan importante es la relación entre la lengua checa y la sociedad que hace uso de ella que, la gente llama "kafkianas" las situaciones absurdas y «Švejkianas» la picardía de los ciudadanos para afrontar la violencia con humor. Václav Havel confiesa que los extranjeros nunca han entendido cómo el pueblo checoslovaco fue capaz de soportar cuarenta años de totalitarismo, y añade que en Bohemia los acontecimientos dolorosos siempre se han mezclado con el sentido de la ironía, del ridículo o del humor negro ${ }^{8}$. En una de sus obras teatrales, "Audiencia", Havel intenta describir la situación de un escritor que no puede publicar sus obras y que se ve obligado a trabajar en una fábrica de cerveza: "iQué paradoja, ¿ verdad?»?.

El gran poeta checo, Jaroslav Seifert, que en 1920 se declaraba comunista, fue expulsado del partido en 1929 por haber firmado junto a otros escritores una carta de protesta contra las actuaciones de sus dirigentes. En 1956, cuando tomó la palabra para dirigirse a los miembros de la Unión de Escritores, les recordó que fuesen realmente la conciencia del pueblo, porque temía que habian dejado de serlo desde hacia unos cuantos años y que incluso no habian sido la conciencia de ellos mismos. La

KLima, Ivan: "Duch Prahy», en "Neboite se češtiny". Adamovicová. Praha. Univerzita Karlova.1997. pág. 205.

HAVEL, Václav: “Interrogatoire à distance”. Eds. de l'Aube. 1989. pág. 147

9 HAvel, Václav: «Audiencia». Barcelona. Galaxia Gutenberg. Círculo de Lectores. pág. 311. 
palabra del escritor tiene que comprometerse. Algunas personas pueden silenciar la verdad por conveniencia, pero si el escritor guarda silencio ante la verdad, está mintiendo ${ }^{10}$.

Seifert fue fiel a la verdad durante el resto de su vida. Firmante de la "Carta 77 ", formó parte de los escritores que enriquecieron la literatura "Samizdat" ante la imposibilidad de publicar de manera oficial. Pero en 1984 , por esa ironía que tan bien caracteriza a los escritores checos, obtuvo el premio Nobel de Literatura, ante la sorpresa de las autoridades que tuvieron que apresurarse para publicar oficialmente sus poesias, hasta entonces editadas en "samizdat".

El golpe comunista de febrero de 1948 significó el fin del sistema democrático en Checosiovaquia. Muchos escritores recibieron con entusiasmo el nuevo régimen político. Milan Kundera explica su entusiasmo por formar parte de un grupo de intelectuales llamados a cambiar el rumbo de la historia. En las universidades, los estudiantes comunistas emprendieron la tarea de reformar el sistema: «Era la embriaguez del poder, la ocasión de poder saltar por encima de la historia, trasformándola, e inaugurar una nueva época de la humanidad" "Muchos jóvenes encontraron en la revolución de 1948 una respuesta a sus inquietudes, una seguridad en el período incierto de la adolescencia" "

Uno de los personajes de Ivan Klíma explica los esfuerzos que tuvo que realizar para impresionar a su amiga y para adoctrinarla sobre la nueva sociedad: «Porque tenía una edad en la que uno es todavía capaz de compartir el entusiasmo de los ideales revolucionarios y de los cambios radicales, una edad en la que uno considera los hechos - que a numerosas personas sensatas llenaban de horror-como pequeños desaciertos que no le emocionan. Queria convencerla de la emocionante trascendencia de nuestra época que había liberado a los trabajadores. Mi empeñó fue - como más tarde comprendí- totalmente inútil, porque ella había conocido la trascencendencia del cambio revolucionario desde el lado opuesto. A sus padres les quitaron su pequeña empresa, encarcelaron a algunos de sus parientes, y a ella no le permitieron estudiar en la universidad. ¡Valiente liberación!» ${ }^{12}$.

\footnotetext{
10 "Eastern and Central Europe". Ed. by James Naughton. Series Foreword Margaret Drabble. London. 1995. pág. 133.

11 Kunoera, Milan: "La broma". Barcelona. Seix Barral. 1994. pág. 82, y Kundera, Milan: "La vida está en otra parte", Barcelona. Seix.Barral. 1989. pág. 223.

KLima, Ivan: “V útery ráno (sentimentálni povidka)", en "Má Veselá Jítra». Praha. Rozmluvy. 1990, pág. 27.
} 
Son numerosas las razones que podrían justificar el comportamiento de muchos escritores que colaboraron con el régimen comunista después de 1948. El hecho de que el ejército soviético liberara una gran parte del pais en 1945, la vergüenza de Munich y el sometimiento de las potencias occidentales a las ambiciones de Hitler, hicieron que los jóvenes escritores sucumbieran a la ilusión de ese mundo más justo prometido por los comunistas ${ }^{13}$. Creyeron en el mito del proletariado porque sentían la culpabilidad de clases. Atrapados por su destino se derrumbaron y aceptaron la censura y la autocensura.

Los «idealistas" que se habían afiliado al partido comunista durante la invasión nazi y que no se sometieron al control de las autoridades, representaban un peligro para el nuevo régimen. Muchos eligieron el camino del exilio, otros fueron encarcelados o incluso condenados a muerte como el intelectual marxista Záviš Kalandra, que se había separado de los comunistas como protesta contra los procesos de Moscú ${ }^{14}$. La última generación de censurados fue la de Milan Kundera, Ludvík Vaculík, Ivan Klíma y Pavel Kohout. Desengañados del sueño socialista abandonaron el partido comunista y se hicieron críticos con su pasado.

En 1956, durante el XX Congreso del Partido Comunista de la URSS, Kruchev sacó a la luz un informe sobre los crímenes cometidos por Stalin. A partir de ese momento comenzó en la mayoría de los países del este la desestalinización. Como explica Pavel Kohout: «Kruchev destapó la botella y se escapó el genio". En Checoslovaquia la desestalinización se inició con posterioridad, cuando a principios de los años sesenta se publicó el informe Kolder que revelaba los excesos cometidos durante la época estalinista ${ }^{15}$.

A partir de entonces el mundo cultural checo se desligó del marxismo. La primera vez que pudo hablarse públicamente sobre la obra de un escritor checo, judío y de lengua alemana, fue en 1962 durante el coloquio organizado por el celebre germanista, el profesor E. Goldstücker, sobre la obra y la vida de Franz Kafka, silenciado por los comunistas en 1948, porque escribía sobre la protesta del individuo contra las oscuras maniobras del poder. Algunos años después, novelas como "El Hacha" de Ludvík Vaculik, "La Broma", de Milan Kundera, "Los Cobardes" de Josef Skvorecky, las obras de teatro de Václav Havel o las películas de Jiŕi Menzel empezaron a cuestionar el sistema.

13 Kundera, Milan: «La vida está en otra parte». Barcelona. Seix.Barral. 1989. pág. 223.

14 El poeta Jiri Kollar y Jiri Mucha, hijo del pintor Alfons Mucha fueron enviados a campos de concentración. Vid: Rupnik, Jacques: «L'autre Europe». Paris. Odile Jacob. 1993. pág. 271.

15 Kohout, Pavel: “¿Dónde está enterrado el perro?». Barcelona. Plaza y Janés. 1990. pág. 17. 
Los intelectuales fueron los primeros en ponerse a la cabeza del "proceso de renovación" que conduciría a la Primavera de Praga. En 1967 el economista OtaŠik publicó el libro «Plan y mercado bajo el socialismo", en el que señalaba las medidas que deberían ser tomadas para corregir los errores de la economía planificada. Sin embargo, lo más importante y novedoso fue que para descentralizar la economía, el grupo de reformadores comprendió que también era necesario descentralizar la política e iniciar una democratización de las instituciones ${ }^{16}$.

Los reformadores formaban parte de la generación que tenía veinte años cuando se produjo el golpe comunista de 1948. No estaba marcada por la vergüenza de Munich y por ello repudiaba la prudencia de sus mayores que colaboraron con el Protectorado impuesto por los nazis. Al término de la guerra, la mayoría de los jóvenes creyeron en la oportunidad que les brindaba el nuevo régimen para liquidar el pasado y construir una sociedad más igualitaria. Imbuidos del mesianismo comunista aceptaron en silencio las purgas de los años cincuenta porque las creyeron justas y necesarias. Sin embargo, sus posturas fueron evolucionando con el paso de los años. Por un lado, seguían aceptando la tradicional ideología comunista, pero al mismo tiempo se oponían al inmovilismo de sus dirigentes y empezaron a alimentar esperanzas de cambio ${ }^{17}$.

En los años sesenta esa generación empezó a distanciarse del partido comunista y "se rebeló contra su propia juventud" ${ }^{18}$. Los reformadores no habian perdido la esperanza de cambiar la sociedad, pero como diria años más tarde el principal ideólogo de la Primavera de Praga Zdeněk Mlynár: «En el fondo éramos tontos, y nuestra tontería fue la ideología del comunismo reformista. El comunismo no se podía reformar. Tenía que hundirse solo» ${ }^{19}$.

El 29 de junio de 1967, el escritor Ludvík Vaculík pronunció un discurso durante el Congreso de la Unión de Escritores, en el que contrastaba la visión optimista de los logros socialistas, con los catastróficos resultados políticos, económicos y sociales. Sus palabras fueron críticas con un régimen que, en lugar de cambiar lo que la gente veía, se empeñaba en cambiar sus ojos. Por primera vez, un escritor miembro del partido comunista manifestó abiertamente el desconterito de los ciudadanos y, recogiendo la tra-

16 STOKES, Gate: "The Walls came tumbling down». Oxford. Oxford University Press. 1993. pág. 9 .

MLYNAŘ Zdeněk: "Le froia vient de Moscou". Paris. Gallimard. 1981. pág.124

Kundera, Milan: "Le livre du rire et de l'oubli”. Paris. Folio.Gallimard. 1985. pág.138-173.

MLYNAR Zdenék: op. cit. pág. 305. 
dición de los intelectuales checos frente al poder, alentó a otros escritores para que no olvidasen el papel que la historia les habia encomendado ${ }^{20}$.

Alexandr Dubček, Secretario general del partido comunista eslovaco, formaba parte del grupo opuesto a la política del entonces Presidente Novotny. En enero de 1968, ante las dudas de unos y las presiones de otros, Antonín Novotny tuvo que dimitir. El nombramiento de Dubček como Primer Secretario fue un compromiso de última hora entre reformadores y conservadores y fue literalmente empujado para que aceptase el cargo. Dubcek era un personaje desconocido para los checos y fue recibido con cierto escepticismo. Creía en la posibilidad de reformar el comunismo y de encontrar una vía propia para hacer frente a la crisis económica y al descontento de la sociedad. Sin embargo, debido a la inestabilidad del pais, a la ideología de los reformistas y a la inexperiencia política de Dubček, la revolución dirigida desde arriba se le fue de las manos y la sociedad checa puso en marcha su propia revolución.

Muchos escritores que hasta entonces habían estado marginados encontraron un espacio donde expresar sus ideas. Surgieron numerosas asociaciones deseosas de emanciparse del sistema y de participar en la vida pública, tales como el grupo de los sin partido, "KAN», el "Club 21 ", formado por antiguos prisioneros políticos, o el "Círculo de escritores independientes", del que Havel fue elegido presidente.

El nuevo sistema introducido por los «dubčekistas", el Programa de Acción, hubiera llevado a la sociedad checa a un estado de semi-libertad, a un sistema político parcialmente democrático, la "democratura", que prohibe el pluralismo político, pero permite algunas esferas de libertad. Pero al no legalizar el pluralismo ideológico, el "socialismo con rostro humano" dio entrada a todo tipo de formas políticas antidemocráticas.

Los reformadores comparaban el Programa de Acción con un río que tiene diferentes corrientes, remolinos y rápidos. El caudal está determinado por el cauce que forman los meandros a través del país y que conduce a la desembocadura. En su opinión, ese río, con sus corrientes internas y remolinos, representa las presiones y los conflictos entre las organizaciones sociales, y, evidentemente, el cauce era para ellos el partido comunista.

La ingenuidad de los reformadores les impidić ver que el milagro del 68 conducía al desastre. "¿Cómo es posible el agradecimiento de un pueblo a un ladrón que, por razones poco claras, le devuelve la propiedad robada?

20 Vaculik, Ludvik: "La entermedad del poder", en Pavel Tigrid: "Le Printemps de Prague" Paris. Seuil.1968. págs. 151-164. 
¿Cómo es posible que el pueblo vuelva a confiar en él?", se pregunta el escritor Josef Škvorecky. En su opinión, Dubček era un comunista honrado, pero demasiado ingenuo ${ }^{21}$.

La indecisión de Dubček alarmó a las autoridades soviéticas ante el cariz que tomaban los acontecimientos. "Los dirigentes checoslovacos hacían concesión tras concesión esperando salvar los muebles, pero en realidad estaban serrando la rama sobre la que estaban sentados", así es cómo Václav Havel y el resto de la sociedad comprendieron mucho antes que los reformadores la amenaza de una intervención ${ }^{22}$.

La postura de Dubček fue muy ambigua. Presionado por la sociedad civil y obligado a mantener sus compromisos con la URSS, no supo tomar una decisión. "No eligiendo, dejó a Moscú elegir en su lugar», concluye Petr Pithar ${ }^{23}$.

El 27 de junio de 1968, Ludvík Vaculík lanzó el manifiesto «Las 2.000 palabras" en el que exigía una democratización radical del régimen, y ante la amenaza de una invasión, pedía firmeza a los ciudadanos y apoyo a Dubček. Inicialmente fue firmado por los intelectuales, pero más tarde añadieron sus nombres tal cantidad de ciudadanos anónimos que nunca pudieron contarse las firmas ${ }^{24}$. El manifiesto terminaba con unas palabras proféticas: "La primavera ha terminado y nunca regresará. En invierno ya veremos lo que pasa» 25 .

Viendo el peligro que representaba el experimento checoslovaco, la URSS puso en marcha la "Operación Danubio". Medio millón de hombres pertenecientes a las fuerzas del Pacto de Varsovia invadieron Checoslovaquia el 21 de agosto. Dubček y varios miembros de su gobierno fueron secuestrados y conducidos a la Unión Soviética. Sin embargo, en ausencia de sus líderes, la sociedad empezó a manifestarse más libremente y de forma pacífica. Fue esa actitud la que saivó la vida a Dubček y la que obligó a los dirigentes soviéticos a negociar las bases de un acuerdo ${ }^{26}$.

2) SKVORECKY, Josef: “Talkin' Moscou Blues». London. Faber and Faber. 1998. pág. 237

22 HAVEL, Václav: «La Citoyenneté retrouvée», en: «Le Printemps Tchècoslovaque». Bruxelles. Ed. Complexe. 1999. pág. 12

23 Pithar fue miembro del partido comunista hasta 1968, pero después de la invasión soviética perdió su puesto como profesor en la universidad. Firmante de la «Carta 77 ", en algunas ocasiones fue crítico con sus actividades.

24 Kundera, Milan: "La insoportable levedad del ser". Barcelona. Tusquet. 1997. pág. 304.

25 En opinión de Vaculík, la Primaverá de Praga sigue teniendo una gran importancia en la ac¿ualidad, porque la sociedad se olvidó de sus intereses personales para realizar un trabajo en común. «Mereció la pena el precio que tuvo que pagar, porque era algo necesario. Algunos soportaron la prueba, otros no". En Radio Free Europe, "The 1968 Invasion and its meaning to today's Czechs". 1998.

26 Duplan, Ch. y Giret, V: «La Vie en rouge». Paris. Seuil. 1994. Vol. I. pág. 439. 
En opinión de Pavel Kohout, las potencias aliadas del Pacto de Varsovia no ocuparon Checoslovaquia para defender el socialismo amenazado, sino para defender a los estalinistas amenazados que volvieron a encerrar «el espíritu del genio". Durante algunos meses después de la invasión, la sociedad disfrutó de una cierta libertad. Las nuevas autoridades mantuvieron las fronteras abiertas para que pudieran marcharse aquellos que consideraba molestos. Pero cuando se dieron cuenta de que el éxodo se llevaba a los espíritus más creativos, cerraron las fronteras para que aquellos que no estaban dispuestos a someterse, conociesen el precio que tendrian que pagar $^{27}$.

Pero cuando el 28 de agosto un Dubček humillado regresó a Praga y se dirigió por radio a la población, era evidente que Checoslovaquia tenía que inclinarse ante el invasor. "Las pausas de su discurso y sus palabras entrecortadas mostraron al país que, a partir de ese momento, también estaría obligado a tartamudear, a buscar el aliento para sobrevivir en medio de la humillación", escribe Kundera ${ }^{28}$.

La agonía de la Primavera de Praga empezó en el mes de septiembre con el inicio de la «normalización». Como afirmó Havel: «El barco estaba a punto de naufragar, pero los pasajeros todavía estaban autorizados a gritar que se hundian" ${ }^{29}$. Ese fue el sentido que llevó al joven estudiante Jan $\mathrm{Pa}$ lach a inmolarse por el fuego en enero de 1969, y que simbolizó la desesperación de toda la sociedad. El gesto de Palach no iba dirigido contra las autoridades soviéticas, sino contra la debilidad de los dirigentes checoslovacos que con tanto entusiasmo habían apcyado. "Estamos con vosotros, estad con nosotros", fue el slogan más popular después de la invasión.

Con la «normalización», el país entró en una época de tinieblas, de frustraciones, de apatía, de resignación. El ciudadano ya no estaba obligado a creer en el comunismo, sino a convivir con el partido. Se pasó del postulado "quién no está con nosotros está contra nosotros", a la teoría lanzada en 1956 por el dirigente húngaro, Janos Kadar, "quién no está contra nosotros, está con nosotros" ${ }^{30}$. Sin embargo, el partido siguió manteniendo el monopolio económico, el reparto de riquezas, de promociones, de empleos, en función de la fidelidad de los ciudadanos. Fue un arma más poderosa que la violencia porque cuando fue utilizada, el socialismo se había convertido en una sociedad de consumo.

KOHOUT, Pavel: "Dónde está enterrado el perro». op. cit. pág. 17.

Kundera, Milan: "L'insoutenable légèrté de l'être". Paris. Folio. 1987. pág. 45.

HAVEL, Václav: "Intérrogatoire à distance». Paris. Ed. de l'Aube. 1989. pág. 33.

FEuTÖ, François: "La fin des démocraties populaires". Paris. Seuil. 1992. pág. 78 
La sociedad tuvo que enfrentarse con el dilema permanente, entre aceptar el sistema y vivir con tranquilidad, o por el contrario, oponerse a él y correr el riesgo de perder un bienestar relativo. «El individuo había caído en la trampa de un mecanismo diabólico", escribe Havel ${ }^{31}$. Se trataba de un sistema que Šmečka califica como "violencia civilizada». Violencia, porque la sociedad vive siempre bajo la amenaza, civilizada, porque es aceptable. Frente a esa "violencia civilizada", los disidentes adoptaron la «resistencia civil», que era una forma de oposición no violenta. De ese modo, la sociedad se adoptó a las condiciones del régimen, el poder a un cierto grado de tolerancia y la disidencia a las exigencias del sistema totalitario ${ }^{32}$. El ciudadano dejó de protestar para no caer en el "suicidio social colectivo", pero que inevitablemente le conducía al "suicidio social individual». La sociedad se había «normalizado» ${ }^{33}$.

La "normalización» realizada por Gustáv Husák fue mucho más represiva que la adoptada en los países vecinos. Aunque este término puede tener diferentes significados, en función de las circunstancias históricas y de quienes lo utilizaron, en Checoslovaquia se tradujo por el restablecimiento del control soviético y el dominio del partido comunista ${ }^{34}$. El hecho de que Husák hubiera sido una de las víctimas de las purgas de Stalin y de que apoyara inicialmente las reformas de Dubček, hizo pensar que la "normalización» se realizaria de forma parecida a la de Janos Kadar en Hungría, cooperando con los intelectuales y alejando a la vieja guardia estalinista. Sin embargo, una vez en el poder, erradicó las reformas llevadas a cabo por Dubček, llamó a los estalinistas más radicales y realizó una política de control absoluto sobre los ciudadanos y las instituciones. Como decian en Praga: "Hemos sufrido por Husák y bajo Husák" ${ }^{35}$.

Los intelectuales fueron los primeros en convertirse en víctimas propiciatorias. «Por su duración y por su amplitud, por su carácter sistemático, la masacre de la cultura checa después de 1968 no tiene equivalente en la historia del país desde la Guerra de los Treinta Años", escribió Kundera. De «Biafra del espíritu», calificó Louis Aragon la depuración de intelectuales ${ }^{36}$.

Havel, Václav: "Nouvelle alternative». n." 21. mars. 1991. pág. 42.

Simečka, Milan: "Le rétablissement de l'ordre». Paris. Maspéro. 1979. pág. 130.

JAMEK, Václav: "Traité des courtes merveilles". Paris. Grasset. 1989. pág. 43.

KIERAM, Williams: "The Prague Spring and its aftermath". Cambridge. Cambridge University Press.1997. pág. 40.

CASANOVA, Marina: "La revolución de terciopelo y el movimiento intelectual checoslovacow, en Espacio, Tiempo y Forma. Madrid. UNED. 1997. pág. 372.

36 Kundera, Milan: Ver Rupník, Jacques: “L'autre Europe». Odile Jacob. 1993. pág. 288 
Sin embargo, el proceso de renovación cultural que se había iniciado durante la Primavera de Praga, no desapareció con la invasión. La tradición cultural de finales del siglo XIX y de la I República, sobrevivió a la represión en las obras de numerosos intelectuales que empezaron a escribir en un nuevo espacio de libertad interior ${ }^{37}$. Václav Havel, que estuvo varias veces encarcelado, escribe que antes de ser detenido por primera vez, vivia en un estado de angustia permanente, no sabia qué debía escribir, adónde ir, hasta que fue detenido. Entonces, frente a la pérdida de la libertad física, encontró su libertad moral ${ }^{38}$.

La represión emprendida por Husák tuvo un resultado contrario al esperado. Los disidentes empezaron a buscar nuevos caminos, dentro de la legalidad, para salir de un régimen impuesto por la fuerza de los tanques. Muchos intelectuales fueron depurados, privados de sus trabajos y sin posibilidad de publicar sus obras, pero sólo un grupo muy reducido se integró en la oposición activa. La mayoría prefirió realizar su autocrítica para poder seguir publicando. "Tengo un amigo más joven que yo", escribe Klíma, "que cuando era estudiante le consideraban como una gran promesa de la filosofía checa. Hoy trabaja como vigilante nocturno en el departamento de filosofía de la Academia de Ciencias. Este es un buen ejemplo del absurdo de nuestra vida actılal» ${ }^{39}$.

A mediados de los años setenta la oposición al régimen se habia consolidado y la sociedad había aceptado la manipulación de los "normalizadores". Ante la pasividad de los ciudadanos, Havel dirigió una carta el 8 de abril de 1975 a Husák, en la que denunciaba el miedo de los ciudadanos ante un régimen opresivo que les había obligado a ser indiferentes, a no luchar por nada y que sólo les permitía ocuparse de su vida privada. La importancia de la carta radica en que, por primera vez después de la invasión, un intelectual tomaba la palabra para contestar el poder de Husák. Su contenido fue fotocopiado y difundido en todo el pais y en el resto del mundo en forma de "Samizdat", y marcó el inicio de una nueva etapa para la historia del país ${ }^{40}$.

Empezaron a circular numerosas cartas de protesta que la gente leía y que, en cierto modo, daban sentido a sus vidas. Una de las cartas que mejor refleja la situación del mundo cultural checo y la de los intelectuales,

37 Rubes, Jan: "La polysémie du Printemps de Prague", en "Le Printemps Tchècoslovaque.

1968". Bruxelles. Complexe. 1999. pág. 131

38 HAVEL, Václav: Intérrogatoire. op. cit. pág. 189

39 Klima. $V$ útery ráno. op. cit.

40 Kriseova, Eda: "Vaclav Havel. El reto de la esperanza». Madrid. Espasa Calpe. 1993. pág. 142. 
es la que el filósofo Karel Kosík dirigió a Jean-Paul Sartre cuando le fueron confiscados sus trabajos de largos años: "Soy un simple cero y por ello no puedo enseñar filosofía en la universidad, ni desarrollar mi trabajo en ninguna parte. Estoy muerto. Todas mis publicaciones han sido prohibidas, retiradas de las bibliotecas, y mi nombre ha sido tachado de la lista de autores. No existo. En tanto que filósofo y autor, estoy encerrado vivo en mi patria. En tanto que ciudadano, me han privado de mis derechos fundamentales y sólo vivo como una persona bajo sospecha permanente» ${ }^{41}$.

No es extraño que muchos intelectuales tomaran el camino del exilio. Milan Simečka recoge en una de sus obras la triste despedida del historiador Vilém Prečan el 11 de julio de 1976: "La decisión de marcharse del país fue madurando a lo largo de los años, en los que el historiador pasó muchas noches en vela, trabajando en el transformador eléctrico de un hospital, mientras se preguntaba qué sentido tenía todo; mientras acudía a los interrogatorios en la cárcel de Ruzynè; cuando escribía cartas a las autoridades y no obtenía respuesta; cuando le despidieron del club nocturno donde trabajaba como guardarropas. Pero su decisión maduró definitivamente, cuando se dio cuenta de los años que había perdido sin poder dedicarse a su trabajo de historiador " ${ }^{42}$.

Otros intelectuales como Prečan, tampoco pudieron soportar por más tiempo la asfixiante situación de los perseguidos y decidieron abandonar el país. Porque no pcdían publicar sus obras, porque negaban a sus hijos la posibilidad de estudiar en la universidad, porque incluso les despedían de aquellos trabajos manuales que se habian visto obligados a realizar para poder sobrevivir. Para los que se quedaron cada separación significaba debilitarse un poco más. Para los que se fueron, la incógnita de un futuro incierto alejados de su cultura ${ }^{43}$.

En enero de 1977 se creó la "Carta 77" que reunió a un heterogéneo grupo de personas que reclamaba la aplicación de los derechos humanos en Checoslovaquia, y que el propio gobierno había ratificado en el Acta final de los Acuerdos de Helsinki. Tomó el nombre de "Carta", en referencia a la "Carta Magna" inglesa otorgada por Juan sin Tierra en 1215, y a la "Carta de las Naciones Unidas». El nombre fue sugerido por el escritor Pavel Kohout ${ }^{44}$. Aunque dentro de un círculo muy reducido de intelectuales, la «Carta

41 En Novak, Miroslav: "Du Printemps de Prague au printemps de Moscou». Genêve. George. Ed. 1990. pág. 196.

42 Simečka, Milan: "Fejeton o loučeni». Köin. INDEX. 1984. pág. 34.

43 Vaculik, Ludvík: "Cesky snár". Atlantis. 1981. El mejor libro para conocer la vida de los intelectuales disidentes en Chiecoslovaquia en los años setenta.

44 Havel, Václav: “Dálkovy Vyslech».Praha. Melantrich.1989. pág. 118. 
77", se convirtió en un simbolo de esperanza y en un foco de anticonformismo, pero no supuso una amenaza para el régimen. En opinión de Havel, cualquier observador extranjero que desconociera la realidad del país, sería incapaz de comprender de qué se quejaban los firmantes de la “Carta $77 » 45$.

Paradójicamente, su origen nada tuvo que ver con las actividades de los disidentes, sino con las de los miembros de un grupo musical "underground", "The Plastic People of the Universe", que fueron detenidos por la policía e inculpados según el párrafo 202 del Código penal, por desorden y agitación pública ${ }^{46}$. Era un grupo de jóvenes sin ningún pasado político que habían crecido bajo el régimen comunista y que sólo querían vivir y expresarse libremente. Algunos disidentes emprendieron una campaña a su favor y lograron unir a las diferentes corrientes de oposición al régimen. El juicio, que se inicio en la ciudad de Pilsen en julio de 1976, pronto adquirió un carácter internacional y sorprendió a las autoridades que vieron unirse a las protestas a antiguos miembros del partido. El espíritu de solidaridad surgido durante el juicio mostró que la libertad es indivisible, y que un ataque a la música "underground" era un ataque a la vida en la verdad ${ }^{47}$.

El texto de la "Carta 77" fue entregado a la Asamblea y al Gobierno federal y, una vez que se hizo público, empezaron las detenciones de sus portavoces, Jiłí Hájek, Václav Havel y Jan Patočka, que moriría como consecuencia de una hemorragia cerebral después de haber sido sometido a largos interrogatorios, así como la de otros firmantes del documento. Muchos de ellos fueron interrogados y sus casas registradas. Pero cuando la policia descubrió que sólo poseían libros e ideas, les expulsaron de sus trabajos, les retiraron el pasaporte, les cortaron el teléfono. Fue el inicio de una lucha entre los que defendian la justicia de sus reivindicaciones, y los que imponian su autoridad y su fuerza ${ }^{48}$. Para Patocḱka la moral humana tiene que ser incondicional para que el hombre sea hombre, pero no para que la sociedad funcione: "es necesario actuar con dignidad, no dejarse intimidar. Es necesario decir la verdad" 49.

Los escritores checos se dividieron entre los que aceptaron la «normalización" para conseguir que sus obras se publicaran, y los que se vieron

45 William A. Henry: «Dissident to President», en TIME. January, 8, 1990.

46 Havel, Václav: “202», en “Sólo pro psaci stroj». Köln. INDEX. 1984. pág. 123.

47 Havel, Václav: “El poder de los sin-poder». Madrid. Ed.Encuentro.1990. pág. 52.

48 KLima, Ivan: “My Golden Trades”. London. Pinguin Books. 1990. pág. 104.

49 Laiguel-Levastine, Alexandra: “Jan Patočka, l'esprit de la dissidence». Paris. Michalon. 1998. pág. 25. 
obligados a escribir para "el cajón" encerrándose en el ghetto de su anticonformismo. No tenían lectores ni competencia creativa. Era un pequeño grupo de «idealistas» que se convirtió en un símbolo de esperanza para la mayoría silenciosa ${ }^{50}$.

En 1968, el escritor Ivan Klíma, que se encontraba en una universidad americana, decidió regresar al ghetto de la Checoslovaquia "normalizada", precisamente él, que durante la guerra estuvo encerrado, siendo un niño, en el terrible ghetto de Terezín. Cada primer domingo de mes, invitaba a su casa a aquellos escritores censurados por el régimen, organizando tertulias literarias en las que se leían sus obras unos a otros. La policía, alertada por esas reuniones, ordenó a Klíma que las anulase. Fue el inicio de la literatura "Samizdat» ${ }^{51}$.

El género "samizdat" surge cuando el escritor pierde su libertad y realiza su obra en circunstancias difíciles sin esperar ninguna recompensa 52. Asi lo entiende Vaculík cuando escribe: "La libertad humana, más amplia que la llamada libertad política, se siente con más fuerza en los regímenes represivos que en los liberales, donde la necesidad de libertad no es resentida tan profundamente, y donde no existe la necesidad de definirla» ${ }^{53}$.

En 1972, Ivan Kiíma hizo varias copias a máquina de su obra "Leprosos" para distribuirlas entre aquellos que estuvieran interesados. Fue entonces, cuando Ludvík Vaculík, siguiendo el ejemplo de Klíma, hizo varias copias de su libro "El Cobaya", no sólo con la idea de distribuirlas entre los amigos, sino para crear una editorial al margen de los círculos oficiales. Escogió el nombre de “Edice Petlice» -Ediciones Candado-. Cada uno de los asistentes se comprometió a escribir a máquina con varias copias sus manuscritos que deberian ir firmados, con la idea de que de ese modo no serían perseguidos y expuestos a condenas decretadas por las leyes de publicación. Vaculík corrige los manuscritos, recorre la ciudad de Praga cada día con su cartera repleta de libros, los lleva a encuadernar, los distribuye, acude con regularidad a los interrogatorios de la policía, protege a las personas que con la espalda torcida y los nervios destrozados, han copiado los manuscritos. «Edice Petlice» empezó publicando breves ensayos literarios, pero pronto empezaron a editarse tam-

\footnotetext{
Škvorecky, Josef: “Talkin Moscow Blues". London. Faber and Faber. 1989. pág. 241. KoHout, Pavel: «Dónde está enterrado el perro". Barcelona. Plaza y Janés. 1990. pág. 17

s HAJEK, Igor: "Samizdat literature", en "Good-bye samizdat". Illinois. North Western Uni-

Vaculik, Ludvík: "Dzin", en "Sólo pro psací stroj”. Köln. INDEX. 1984. pág. 38.
} versity Press. 1992. pág. 3 
bién libros. Las ediciones fueron mejorando la encuadernación y la impresión, y también aumentaron las tiradas y los lectores. "Edice Petlice" llegó a publicar alrededor de 400 títulos de autores relacionados por un pasado común ${ }^{54}$. Se crearon nuevas editoriales, tales como "Kvart» de Jan Vladislav, que publicó 120 títulos antes de exilarse, o "Expedice" de Václav Havel y Jan Lopatka, que eran quienes decidian sobre los libros que debían publicarse y no los autores ${ }^{55}$. De ese modo, Havel aparecia como el único responsable ante las autoridades. Cuando fue detenido y condenado a cuatro años, su esposa Olga asumió la responsabilidad de las publicaciones firmando los manuscritos ${ }^{56}$.

Con el tiempo la literatura "samizdat" se abrió a los filósofos, a los historiadores, a los sociólogos y a todos aquellos censurados por el régimen. Muchos de esos "samizdat" fueron enviados y publicados en el extranjero, como hicieran Zdena y Josef Škvorecky en su editorial "SixtyEight Publishers» en Toronto, 0 "Index» en Colonia ${ }^{57}$.

La literatura "samizdat" permitió a los autores liberarse de la censura, o mejor dicho, de la auto-censura, y a constituirse en un contrapoder, "el poder simbólico de la palabra escrita y del desafío moral" ${ }^{58}$. La policía confiscaba los manuscritos en los numerosos registros domiciliarios, detenía a los copistas e incluso les encarcelaba. Jif́i Grửa fue encarcelado porque escribía. Solamente escribía. "¿Quién tendría interés en vivir en un pais donde la creación literaria es considerada como un delito, donde un fiscal puede juzgar lo que es arte y lo que es un delito?", se pregunta Jaroslav Hutka y añade: "el poder que juzga a un poeta se está juzgando asi mismo. Si una nación no es capaz de defender a sus poetas, ¡lo más valioso de la patria!, posiblemente dejará de ser una nación" ${ }^{59}$. Los autores que escribieron en "samizdat" sacrificaron su libertad personal, pero aunque algunos sintieron el deseo de abandonar el papel de "conciencia de la nación", como dice Havel, "no se puede escapar, porque la disidencia se ha convertido en el centro de la resistencia espiritual checa». Uno no se convierte en disidente de un día para otro,

\footnotetext{
54 Vaculik, Ludvik: "A padlock for Castle Schwarzenberg", en "Good-bye samizdat». op. cit pág. 118.

${ }_{55}$ "Expedice" tomó el nombre de la primera imprenta de libros checos, "Česká Expedice", de Jan Václav Kramerius.

56 Una recensión de literatura "Samizdat" en: "Vilém Precan: "Nezávislá literatura a Samizdat $\checkmark$ Cesoslovensku 70 a 80 let" ". Praha. Ústav pro soudobé déjiny.CSAV.1992, y en: Václav Burian: "Ceská a slovenská literatura v exilu a samizdat". Olomouc. Hanácké noviny. 1991

5? SkILling, H.Gordon: «Samizdat and....».op. cit. pág. 31.

58 KLima, Ivan: "My golden Trades". op. cit. pág. 104.

54 HuTKA, Jaroslav: "Grúsuv dotazník». Köln. ÍNDEX. 1984. pág. 158
} 
"sino en el momento en que una persona trata de actuar honradamente según sus principios y es calificado como enemigo de la sociedad", concluye Havel ${ }^{60}$.

El compromiso de los intelectuales checos con los problemas de la sociedad tiene su origen en el rechazo que siempre demostraron por las elites del país. Kafka fue un sencillo empleado en una compañia de seguros, Capek periodista, Hašek y Hrabal pasaron muchas horas buscando la inspiración en lúgubres tabernas, y Vaculík nunca ha dejado de ser un simple ciudadano que denuncia las injusticias de los gobernantes ${ }^{61}$.

La generación de los disidentes estuvo marcada por la injusticia de los gobernantes. Pero esa total arbitrariedad que mantiene a la sociedad atemorizada, hace que el miedo se trasforme en deseos de cambiar la sociedad. Para Klíma "así es como el disidente se convierte en opositor al poder. Aquellos que han luchado por su integridad, por sus principios morales, no pueden ser destruidos por el miedo y nunca podrán vencerles" 62. Son los que Petr Pithar califica de "disidentes de la reflexión", los que tratan de descubrir las razones por las que un sistema totalitario se ha mantenido en el poder durante más de cuarenta años, y critican la aceptación de la violencia civilizada. Frente a ellos, Pithar sitúa a los "disidentes de la protesta", que atrapados entre el engranaje comunista y los "sin poder", por debilidad o por miedo, eran responsables del funcionamiento del sistema y por ello, se habian corrompido moralmente ${ }^{63}$.

Muchos escritores decidieron tomar el camino del exilio. Pero aquellos que permanecieron en Checoslovaquia y quisieron ver sus obras publicadas, tuvieron quie aceptar "dejarse violar un poco para poder seguir viviendo. Aceptar las amarguras, las bajezas" ${ }^{64}$. Bajo tales circunstancias, aquellos que no quisieron comprometerse con la disidencia dejaron de formar parte de los espiritus creativos y se convirtieron en oportunistas. Pero no hay que pensar que todo escritor prohibido fuera un genio, o un escritor oficial un crápula. En algunos casos muchos de ellos siguieron un doble camino, publicando en ediciones "samizdat" y en publicaciones oficiales. Pero para Hrabal, como para muchos escritores "permanecer en

60 Havel, Václav: "Ecrits politiques". Paris. Calman.Levy. 1989. pág. 31

51 Havel, Václav: "A cup of coffee with my interrogator". London. Readers International. 1987. pág. 3.

62 KLIMA, Ivan: “The Spirit of Prague». London. Granta Books. 1992. pág.169.

63 PITHART, Petr: "Les intellectuels au pouvoir: la double dissidence, la double déception aujourd'hui», en Transculturs. Vol. I. 1994. pág. 27.

64 Hrabal, Bohumil: "Lettres à Doubenka”. Paris. Laffont. 1991. pág. 179. 
Checoslovaquia era el único modo de poder realizarse sin interrumpir el contacto con la lengua en continua evolución» ${ }^{65}$.

Klíma considera que un escritor es en cierto modo un aventurero, le aburre la tanquilidad, el orden, el conformismo. No puede abandonar el país porque es el suyo, porque tiene algunos amigos que necesita y que le necesitan, porque la gente habla su mismo idioma y porque, en su opinión, ser escritor significa también ayudar a las personas cuyos destinos le afectan ${ }^{66}$.

El caso de Hrabal es significativo. Cuando en 1975 realizó su autocrítica y pudo publicar en las editoriales oficiales, siguió haciéndolo también en "samizdat". Fue un duro golpe para los escritores perseguidos y para los lectores de Hrabal que copiaban sus obras a máquina. «Estaba leyendo el libro que me habían prestado de Hrabal, "La ciudad donde el tiempo se ha detenido", que alguna buena persona había copiado a mano", escribe Jaroslav Hutka ${ }^{67}$. No es de extrañar que algunos miembros de la cultura subterránea organizarán un auto de fe de sus obras editadas en «samizdat».

En 1978 el entusiasmo de los firmantes de la "Carta 77» había disminuido sensiblemente. Para Vaculík de nada servían los héroes si el resto de los ciudadanos aceptaba en silencio la situación del país. En una crónica sobre el heroísmo, Vaculík escribió una reflexión sobre el valor de las personas excepcionales y el de la masa de ciudadanos anónimos, y discrepaba de las tácticas de algunos de los firmantes de la "Carta 77». El texto dio origen a numerosas polémicas y a cartas de contestación como la escrita por Havel, "Milý Páne Vaculík», - «Querido Sr. Vaculík»-, en la que defendía las acciones llevadas a cabo por los disidentes, aunque implicaran ir a la cárcel. Para Jan Trefulka los héroes son conscientes de sus compromisos humanos. Ante la derrota o ante el fracaso, no saben liberarse con un gesto o con una mueca de cinismo de su debilidad. Ese es el difícil destino de los héroes ${ }^{68}$.

Sin embargo, Vaculík se pregunta para qué sirven los héroes dispuestos a ser encarcelados, si el resto de la población se hunde poco a poco en la humillación, sin darse cuenta de que él es el prototipo del héroe, pero que no quiere serlo. Vaculík se rebela contra los que abandonan el pais, contra los que son encarcelados, contra todo aquello que ha hecho

\footnotetext{
65 Hrabal, Bohumil: "La flûte enchantée", en "Sécrets a métamorphoses". Paris. Autrément. Mai. 1990. pág. 27.

66 KLIMA, Ivan: “V útery ráno" op. cit. pág. 25.

67 HuTKA, Jaroslav: "Grusưư Dotazník", en "Sólo pro psaci stroj”. op. cit. pág. 158.

68 Trefulka, Jan: «Fejeton s práním», en "Sólo pro psaci stroj». op. cit. pág. 199.
} 
disminuir las actividades de los "cartistas" ${ }^{69}$.!Dios mío!, cuántas veces me he dicho que no iba a aceptar más responsabilidades".

Los acontecimientos de 1989 demostraron que los firmantes de la "Carta 77" contribuyeron a minar el apoyo de los ciudadanos al régimen comunista, y que sus dirigentes tuvieron un papel determinante en la creación del Foro Cívico, organización que encauzaría la urevolución de terciopelo" y cuyos miembros formarían el primer gobierno no comunista en Checoslovaquia.

La «revolución de terciopelo» fue la revolución de los intelectuales. A pesar de la atmósfera asfixiante que les impuso la "normalización», sabian que en la lucha para alcanzar la libertad, los primeros disidentes serían encarcelados. Las autoridades no tendrían dificultades «para encarcelar a diez o mil más, pero perderian el poder cuando un millón de personas se opusieran a ellas con obstinación» 70 .

Los disidentes lucharon con la palabra para que "prevaleciese la verdad", para que la historia del pais permaneciese en la memoria de los ciudadanos. Pero los intelectuales no están hechos para ser políticos, como señala Eda Kriseová. Recuerda cómo en la Antigua Grecia muchos hombres, que no eran profesionales de la política, fueron buenos políticos porque se sentían libres de tomar decisiones, porque en realidad no querían ser políticos ${ }^{71}$. Asi es como Havel aparece ante los ojos de Hrabal, como un héroe que, del mismo modo que los héroes de la Antigüedad, había arrebatado el fuego sagrado a los comunistas. Por eso fue a la cárcel. Por eso, llegado el momento, se convirtió en la fuerza motriz de la revolución ${ }^{72}$.

Después de la "revolución de terciopelo" gobernaron los intelectuales porque no había políticos. Los disidentes de la palabra fueron críticos con el poder, pero no sabían poner en práctica sus ideas. Vencieron los intelectuales, pero fueron los pragmáticos los que gobernaron.

"Cuando un escritor escribe, el régimen es el telón de fondo. Si cambia el régimen, quizás haya que cambiar las críticas. Yo escribía para mí, sin intención política, aunque mis obras tuvieran un carácter político. El escritor debe hablar de los problemas humanos. Siempre ha sido asi. La palabra no puede cambiar las cosas, pero el escritor está obligado a repetir las

\footnotetext{
Vaculik, Ludvik: “La Clet des songes». Paris. Actes Sud.1989. págs. 30-35, 395. Ibidem.

En Casanova, Marina: "La revolución de terciopelo". op.cit.

72 SAlmoN, Ctristian: "A bâtons rompus avec Bohumil Hrabal". Paris. Criterion. 1991, pág. 52.
} 
cosas para que permanezcan en la memoria del pueblo". Son palabras de Vaculík que dan significado a todos esos «libros-nolibros» de la literatura "Samizdat» 73 .

En 1968, una de las cantantes más populares de los años sesenta, Marta Kubišová, fue silenciada por los comunistas por su canción «Plegaria por Marta" que decía: "Ahora que el gobierno de tus intereses perdidos vuelve a ti, pueblo, vuelve a ti», que recuerdan las palabras escritas por Jan Comenius en 1650 en su opúsculo "La última voluntad de una madre agonizante", en el que expresaba su amor por la patria, por la lengua y por el pueblo checo: "Como en Dios mismo creo, en que una vez que haya amainado la borrasca de la ira, el gobierno de tus cosas volverá otra vez a tus manos, ;oh pueblo checo!».

«El gobierno de tus cosas vuelve a ti, pueblo» fueron las palabras con las que el primer Presidente de la República, T.G. Masaryk, empezó su discurso ante la Asamblea Nacional Checoslovaca el 22 de diciembre de 1918. "Tu gobierno, pueblo, vuelve a ti", fueron las palabras que pronunció Václav Havel el 1 de enero de 1990, al terminar su discurso como Presidente de Checoslovaquia setenta y dos años después" ${ }^{74}$.

73 Entrevista con Ludvík Vaculík. Bruselas. 30-4-1998.

74 SAYER, Derek: "The coast of Bohemia". Princeton. Princeton University Press. 1998. pág. 270 . 